\title{
PENGARUH JAMINAN SOSIAL TENAGA KERJA TERHADAP PRODUKTIVITAS KERJA KARYAWAN PADA PT SUMBER ABADI INDONESIA CABANG KOTA SORONG PAPUA BARAT
}

\author{
Oleh: \\ AYU OKTATIANI SALIM ${ }^{1}$ \\ RAIS DERA PUA RAWI ${ }^{2}$ \\ Program Studi Manajemen, Fakultas Ekonomi \\ Universitas Muhammadiyah Sorong, Indonesia \\ Email : raisdera207@gmail.com \\ HP. 082248458994
}

\begin{abstract}
ABSTRAK
Tujuan penelitian ini adalah sebagai berikut: Untuk mengetahui pengaruh jaminan sosial tenaga kerja terhadap produktivitas kerja karyawan pada PT. Sumber Abadi Indonesia cabang Kota Sorong. Desain penelitian yang dilakukan dalam penelitian ini adalah penelitian kuantitatif. Adapun pendekatan yang digunakan adalah pendekatan deskriptif dan korelasi. Populasi dalam penelitian ini adalah keseluruhan karyawan pada PT. Sumber Abadi Indonesia yang berjumlah 120 karyawan. Sedangkan sampel yang gunakan dalam penelitian ini yaitu setengah dari jumlah pupilasi atau keseluruhan karyawan, sampel yang di pakai yaitu 60 karyawan. Metode pengumpulan data menggunakan Observasi ( Pengamatan), Metode Angket (Koesioner), Metode Wawancara. Hasil penelitian menunjukan bahwa Hasil perhitungan statistik uji $\mathrm{t}$ menunjukan nilai $\mathrm{t}$ hitung sebesar 3.198 setelah itu dibandingkan dengan nilai $\mathrm{t}$ tabel sebesar 2.002 dengan signifikansi 5\% (0,05). Jadi dapat disimpulkan $t$ hitung $>\mathrm{t}$ tabel $(3.198>2.002)$ dengan signifikansi t 0.002 $<0.05$. ini berarti dimana variabel jaminan sosial tenaga kerja akan meningkatkan produktivitas kerja karyawan. Dari hasil analisis variabel jaminan sosial tenaga kerja bertanda positif dengan kata lain akan meningkatkan produktivitas kerja karyawan. Dengan demikian hipotesis Ha diterima dan H0 ditolak.
\end{abstract}

Kata Kunci : Jaminan Sosial, Tenaga Kerja, Produktifitas Kerja Karyawan

\section{PENDAHULUAN}

Jaminan sosial tenaga kerja merupakan hak asasi manusia, berlaku universal untuk seluruh warga negara, yang bermanfaat untuk memberikan jaminan perlindungan, kesejahteraan dan ketenangan, keamanan dalam melaksanakan hubungan kerja. Jaminan sosial tenaga kerja telah 
menjadi komitmen nasional yang diamanatkan oleh karena itu, Jaminan sosial tenaga kerja melekat sebagai "state obigation” yang dilaksanakan untuk kepentingan tenaga kerja.

Menurut Rais Dera P. Rawi dan Muhammad Arifin Abd. Kadir (2018), dalam penelitiannya menyatakan bahwa Pengelolaan sumber daya manusia tidak lepas dari faktor pegawai yang diharapkan dapat berprestasi sebaik mungkin demi mencapai tujuan kantor pemerintah. Pegawai merupakan aset utama kantor dan mempunyai peran yang strategis di dalam kantor atau instansi yaitu sebagai pemikir, perencana, dan pengendali aktivitas kantor.

Tenaga kerja membantu pihak perusahaan untuk menghasilakan barang atau jasa. Pihak perusahaan diharapkan dapat memberikan pelayanan pemenuhan kebutuhan-kebutuhan karyawan sesuai dengan tujuan karyawan, yaitu untuk mendapatkan upah guna mencapai kesejahteraan dengan diperoleh berbagai fasilitas pemenuhan kebutuhan hidup dengan memberikan pemenuhan kebutuhan hidup tersebut dengan mudah dan baik karena dengan diberikannya pemenuhanpemenuhan kebutuhan karyawan tersebut akan menjamin kehidupan dengan diberikannya jaminan sosial tenaga kerja karyawan.

Untuk memenuhi kebutuhan-kebutuhan karyawan itu perlu adanya suatu program yang dirancang untuk membantu para pekerja dan keluarga mereka ketika pendapatan mereka dihentikan. Serta untuk mengurangi beban pengeluaran perawatan kesehatan, kematian, serta jaminan sosial lainnya.

Salah satu upaya untuk mewujudkan hal tersebut adalah pelaksanaan program jaminan sosial tenaga kerja yang diterapkan melalui undang-undang No.40 tahun 2004 tentang SJSN (Sistem Jaminan Sosial Nasional) dan TAP MPR RI No X/MPR/2001 yang menugaskan presiden RI untuk membentuk sistem jaminan sosial nasional. Jaminan sosial yang diberikan pihak pengusaha terhadap karyawannya didasarkan atas kebijaksanaan-kebijaksanaan yang telah ditentukan. Dalam bentuk peraturan tersebut pada dasarnya mengatur hubungan antara pengusaha dengan karyawannya dalam pemenuhan kebutuhan-kebutuhankaryawan tersebut. Terpenuhnya kebutuhan-kebutuhan ini akan meningkatkan produktivitas kerja seorang karyawan.

Menurut Yustisia (2014: 163) jaminan sosial sebagai program publik, badan penyelenggara jaminan sosial ketenagakerjaan (bpjs ketenagakerjaan) merupakan badan hukam publik yang bertanggung jawab kepada presiden dan berfungsi menyelenggarakan jaminan sosial tenaga kerja bagi seluruh pekerja seluruh Indonesia termasuk orang asing yang bekerja paling cepat 6 bulan di Indonesia. Ruang lingkup program jaminan sosial tenaga kerja dalam undang-undang nomor 40 tahun 2004 ini meliput jaminan kecelakaan kerja, jaminan kematian, jaminan hati tua, jaminan pemeliharaan kesehatan. Menurut Ahmad (2002) produktivitas adalah suatu pendekatan disiplin untuk menentukan tujuan yang efektif, pembuatan rencana, replikasi, penggunaan cara yang produktivitasnya menggunakan sumber-sumber secara efisien dan tetap menjaga adanya 
kualitasyang tinggi. Produktivitas adalah kemampuan suatu faktor produksi dalam bentuk rasio antara jumlah produksi dan jumlah faktor produksi yang dihasilkan dalam waktu tertentu.

Pemberian pelayanan jaminan sosial tidak memberikan perlindungan kepada karyawan, melainkan juga dapat meningkatkan produktivitas kerja karyawan, karena apabila karyawan merasa aman dan mendapat perlindungan baik bagi dirinya maupun bagi keluarganya, yang mana akan mengakibatkan hasil produksi akan meningkat. PT Sumber Abadi Indonesia cabang Kota Sorong bergerak di bidang pengembangan perkebunan dan pengolahan kelepa sawit, dengan demikian PT.Sumber Abadi Indonesia sebagai perusahaan yang sangat memerlukan adanya karyawankaryawan yang produktif.

\section{Rumusan Masalah}

Rumusan masalah pada penelitian ini adalah sebagai berikut: "Apakah Jaminan Sosial Tenaga Kerja Berpengaruh Terhadap Produktivitas Kerja Karyawan Pada PT Sumber Abadi Indonesia Cabang Kota Sorong?"

\section{Tujuan Penelitian}

Tujuan penelitian ini adalah sebagai berikut: Untuk mengetahui pengaruh jaminan sosial tenaga kerja terhadap produktivitas kerja karyawan pada PT. Sumber Abadi Indonesia cabang Kota Sorong.

\section{METODE PENELITIAN}

\section{Desain Penelitian}

Desain penelitian yang dilakukan dalam penelitian ini adalah penelitian kuantitatif. Adapun pendekatan yang digunakan adalah pendekatan deskriptif dan korelasi.

\section{Populasi dan Sampel}

Populasi dalam penelitian ini adalah keseluruhan karyawan pada PT. Sumber Abadi Indonesia yang berjumlah 120 karyawan. Sedangkan sampel yang gunakan dalam penelitian ini yaitu setengah dari jumlah pupilasi atau keseluruhan karyawan, sampel yang di pakai yaitu 60 karyawan.

\section{Metode Pengumpulan Data}

Untuk mengumpulkan data penalitian, penulis menggunakan metode-metode antara lain sebagai berikut : Metode Observasi ( Pengamatan), Metode Angket (Koesioner), Metode Wawancara. 


\section{Teknik Analisis Data}

Teknik analisis menggunakan Regresi Linier Sederhana. Data yang terkumpulkan di analisis dengan pendekatan kuantitatif dan dibantu dngan program SPSS. Rumus persamaan regresi linier sederhana adalah :

$$
\mathrm{Y}=\mathrm{a}+\mathrm{bX}
$$

Keterangan :

$$
\begin{aligned}
& \text { Y : Variabel terikat (Produktivitas ) } \\
& \text { a : Konstanta } \\
& \text { b : Koefisien regresi } \\
& \text { X : Variabel bebas (Jaminan Sosial Tenaga Kerja) }
\end{aligned}
$$

\section{HASIL DAN PEMBAHASAN}

\section{Hasil Uji Validitas}

\begin{tabular}{|c|c|c|c|c|}
\hline No. & Variabel & $\mathbf{r}^{\text {hitung }}$ & $\mathbf{r}^{\text {tabel }}$ & Keterangan \\
\hline & Jaminan Sosial & & & \\
\hline & Tenaga Kerja & & & \\
\hline 1. & Indikator 1 & 0,364 & 0,254 & Valid \\
\hline 2. & Indikator 2 & 0,540 & 0,254 & Valid \\
\hline 3. & Indikator 3 & 0,351 & 0,254 & Valid \\
\hline 4. & Indikator 4 & 0,581 & 0,254 & Valid \\
\hline 5. & Indikator 5 & 0,561 & 0,254 & Valid \\
\hline 6. & Indikator 6 & 0,338 & 0,254 & Valid \\
\hline 7. & Indikator 7 & 0,515 & 0,254 & Valid \\
\hline \multirow[t]{2}{*}{8.} & Indikator 8 & 0,561 & 0,254 & Valid \\
\hline & $\begin{array}{l}\text { Produktivitas } \\
\text { Kerja Karyawan }\end{array}$ & & & \\
\hline 1. & Indikator 1 & 0,295 & 0,254 & Valid \\
\hline 2. & Indikator 2 & 0,642 & 0,254 & Valid \\
\hline 3. & Indikator 3 & 0,342 & 0,254 & Valid \\
\hline 4. & Indikator 4 & 0,290 & 0,254 & Valid \\
\hline 5. & Indikator 5 & 0,674 & 0,254 & Valid \\
\hline 6. & Indikator 6 & 0,507 & 0,254 & Valid \\
\hline 7. & Indikator 7 & 0,314 & 0,254 & Valid \\
\hline
\end{tabular}

Uji validitas digunakan untuk mengukur sah atau tidaknya suatu kuesioner. Suatu item kuesioner di nyatakan valid apabila nilai $\mathrm{r}^{\text {hitung }}>\mathrm{r}^{\text {tabel }}(\mathrm{n}-2)$. Pengujian validitas dapat dilihat dibawah ini :

Table 1. Hasil Uji Validitas

Sumber : Data Primer olahan SPSS 20 
Table 1. hasil uji validitas dapat diketahui bahwa keseluruhan item pernyataan menunjukan bahwa $\mathrm{r}^{\text {hitung }}>\mathrm{r}^{\text {tabel }}$ pada taraf signifiksi $5 \%$, ini artinya setiap penyataan atau indikator variabel dinyatakan valid untuk digunakan sebagai instrumen dalam penelitian atau pernyataan yang diajukan dapat digunakan untuk mengukur variabel yang diteliti.

\section{Uji Reliabilitas}

Metode uji reliabilitas yang paling sering digunakan adalah Cronbach”s Alpha. Suatu variabel dikatakan reliable jika memberikan nilai Cronbach"s Alpha > 0,06.

\begin{tabular}{cc}
\multicolumn{2}{c}{ Tabel 2. Hasil Uji Reliabilitas } \\
\hline Cronbach's Alpha & N of Items \\
\hline .627 & 15 \\
\hline
\end{tabular}

Sumber : Data Primer olahan SPSS 20

Hasil uji reliabilitas menunjukan bahwa semua variabel sudah reliabel dan bisa ditunjukan dengan Cronbach"s Alpha sebesar 0,627 diatas 0,06 sehingga dapat dikatakan semua konsep pengukur masing-masing variabel dari kuesioner adalah reliabel sehingga untuk selanjutnya itemitem pada masing-masing konsep variabel tersebut layak digunakan sebagai alat ukur.

\section{Uji Koefisien Determinasi}

Koefisien determasi digunakan untuk menghitung beberapa besar sumbangan atau kontribusi variabel $\mathrm{X}$ terhadap variabel $\mathrm{Y}$.

\begin{tabular}{lrrrr}
\multicolumn{5}{c}{ Table 3. Hasil Uji Koefisiens Determinasi } \\
\hline Model & R & R Square & $\begin{array}{c}\text { Adjusted R } \\
\text { Square }\end{array}$ & $\begin{array}{l}\text { Std. Error of } \\
\text { the Estimate }\end{array}$ \\
\hline 1 & $.387^{\mathrm{a}}$ & .150 & .135 & 1.69027 \\
\hline
\end{tabular}

a. Predictors: (Constant), JSTK

Pada table 3 menjelaskan bahwa kontribusi jaminan sosial tenaga kerja terhadap produktivitas kerja karyawan menunjukan bahwa nilai koefisien determinasi $\left(\mathrm{R}^{2}\right)$ sebesar 0,150 . Hal ini berarti variabel bebas mempunyai kontribusi secara bersama-sama sebesar $15 \%$ terhadap variabel terikat sendangkan sisanya sebesar $85 \%$ dipengaruhi oleh faktor-faktor lain diluar dari penelitian ini.

\section{Uji Regresi Linier Sederhana}

Analisis regresi linier sederhana adalah hubungan secara linier satu variabel independen (X) dan variabel dependen (Y) analisis ini untuk mengetahui arah hubungan antara variabel 
indenpenden dan variabel dependen apakah pisitif atau negatif. Hasil analisis regresi sederhana dapat dilihat pada tabel berikut ini :

\begin{tabular}{lccccc}
\multicolumn{7}{c}{ Table 4. Hasil Uji Regresi Linier Sederhana } \\
\cline { 1 - 4 } Model & Unstandardized Coefficients & $\begin{array}{c}\text { Standardized } \\
\text { Coefficients }\end{array}$ & t & \multirow{2}{*}{ Sig. } \\
\cline { 2 - 5 } & B & Std. Error & Beta & & \\
\hline (Constant) & 21.472 & 3.465 & & 6.196 & .000 \\
JSTK & .297 & .093 & .387 & 3.198 & .002 \\
\hline a. Dependent Variable: PRODUKTIVITAS & & & &
\end{tabular}

Sumber : Data Primer olahan SPSS 20

Berdasarkan table didapatkan persamaan regresi sebegai berikut:

$$
\begin{aligned}
& Y=a+b x \\
& Y=21.472+0,297 X
\end{aligned}
$$

Persamaan regresi tersebut dapat dijelaskan sebagai berikut : konstanta $(\mathrm{a})=21.472$, Artinya: apabila jaminan sosial tenaga kerja (X) sama dengan nol (tidak ada perubahan) maka produktivitas kerja karyawan PT. Sumber Abadi Indonesia (Y) sebesar 21.472. koefisien regresi (b) = 0,297. artinya : Koefisien Regresi sebesar 0,297 jika jaminan sosial tenaga kerja (X) meningkat sebesar 1 satuan, maka produktivitas kerja karyawan (Y) juga akan meningkat sebesar 0,297.

\section{Uji Parsial (Uji t)}

Kriteria pengambilan keputusan : 1) Bila nilai signifikansi $\mathrm{t}<0.05$, maka $\mathrm{H} 0$ ditolak, artinya terdapat pengaruh yang signifikan antara jaminan sosial tenaga kerja terhadap produktivitas kerja karyawan. 2) Apabila nilai signifikansi t > 0.05, maka HO diterima, artinya tidak ada pengaruh jaminan sosial tenaga kerja terhadap produktifitas kerja karyawan.

\section{Table 5. Uji Parsial}

\begin{tabular}{lccccc}
\hline Model & \multicolumn{2}{c}{$\begin{array}{c}\text { Unstandardized } \\
\text { Coefficients }\end{array}$} & $\begin{array}{c}\text { Standardized } \\
\text { Coefficients }\end{array}$ & t & Sig. \\
\cline { 2 - 4 } & B & Std. Error & Beta & & \\
\hline (Constant) & 21.472 & 3.465 & & 6.196 & .000 \\
JSTK & .297 & .093 & .387 & 3.198 & .002 \\
\hline
\end{tabular}

a. Dependent Variable: PRODUKTIVITAS

Sumber : Data Primer olahan SPSS 20

Berdasarkan hasil tabel diatas didapat $\mathrm{t}^{\text {hitung }}$ sebesar 3.198, dengan derajat kebebasan $(\mathrm{df})=\mathrm{n}$ 2 maka $\mathrm{t}^{\text {tabel }}$ adalah 2.002. karena $\mathrm{t}^{\text {hitung }}>\mathrm{t}^{\text {tabel }}$ dengan tingkat signifikasi 0,002 yang artinya 0,002 < 0,05 maka Ho ditolak dan Ha diterima. Berarti dapat diketahui bahwa jaminan sosial tenaga kerja 
secara signifikan berpengaruh terhadap produktivitas kerja karyawan pada PT. Sumber Abadi Indonesia. Tingkat standar koefisiennya sebesar 0,253 atau 38,3\%.

\section{PENUTUP}

\section{Simpulan}

Dari hasil penelitian maka dapat disimpulkan bahwa :

1. Hasil perhitungan statistik uji koefisien korelasi antara pemberian jaminan sosial tenaga kerja terhadap produktivitas kerja karyawan menghasilkan angka 0.002. nilai tersebut menunjukan angka lebih kecil dari 0.05 maka nilai tersebut berhubungan positif dan signifikan.

2. Hasil perhitungan statistik uji Determinasi kontribusi jaminan sosial tenaga kerja terhadap produktivitas kerja menunjukan bahwa nilai koefisien determinasi $\left(\mathrm{R}^{2}\right)$ sebesar 0.150. hal ini berarti variabel bebas mempunyai kontribusi secara bersama-sama sebesar $15 \%$ terhadap variabel terikat sedangkan sisanya sebesar $85 \%$ dipengaruhi oleh faktorfaktor lain diluar dari penelitian ini.

3. Hasil perhitungan statistik uji $\mathrm{t}$ menunjukan nilai $\mathrm{t}$ hitung sebesar 3.198 setelah itu dibandingkan dengan nilai t tabel sebesar 2.002 dengan signifikansi 5\% (0,05). Jadi dapat disimpulkan $\mathrm{t}$ hitung $>\mathrm{t}$ tabel $(3.198>2.002)$ dengan signifikansi $\mathrm{t} 0.002<0.05$. ini berarti dimana variabel jaminan sosial tenaga kerja akan meningkatkan produktivitas kerja karyawan.

4. Dari data diatas, variabel jaminan sosial tenaga kerja bertanda positif dengan kata lain akan meningkatkan produktivitas kerja karyawan. Dengan demikian hipotesis Ha diterima dan $\mathrm{HO}$ ditolak.

\section{Saran}

1. Diharapkan pihak perusahaan dapat mempertahankan sera meningkatkan pelayanan Jaminan Sosial Tenaga Kerja. Hal ini disebabkan karena variabel Jaminan Sosial Tenaga Kerja mempunyai pengaruh yang positif terhadap produktivitas kerja karyawan. Diharapkan dengan pelayanan yang lebih baik akan meningkatkan produktivitas kerja karyawan PT.Sumber Abadi Indonesia cabang Kota Sorong.

2. Mengingat variabel Jaminan Sosial Tenaga Kerja merupakan hal yang sangat penting dalam mempengaruhi produktivitas kerja keryawan, diharapkan hasil penelitian ini dapat dipakai sebagai acuan bagi peneliti selanjutnya untuk mengembangkan penelitian ini. Namun disarankan untuk menambah variabel indenpenden lainnya selain jaminan sosial tenaga kerja. Yang tentunya dapat mempengaruhi variabel dependen produktivitas kerja 
karyawan. Misalnya semangat kerja dan motivasi dan masih ada variabel-variabel indenpenden lain diluar penelitian ini yang bisa mempengaruhi produktivitas.

3. Kuesioner yang digunakan peneliti masih kurang memadai, oleh karena itu pada penelitian selanjutnya dapat menambah dan memperbaiki pernyataan-pernyataan yang ada dalam penelitian ini.

\section{DAFTAR PUSTAKA}

Adi putra. 2016. Pengaruh jaminan sosial tenaga kerja terhadap produktivitas kerja karyawani. Makassar.

Ahmad, Tohari. 2002. Pemahaman Peraktis Sumber Daya Manusia. Mandar Maju, Bandung.

Arikunto, S.2010. Prosedur Penelitian Suatu Pendekatan Praktik. Jakarta. Rineka Cipta

Asyahadie, Zaeni, 2008. Aspek-aspek Jaminan Sosial Tenaga Kerja di Indonesia. Jakarta. PT. Grafindo Persada.

Bambang Wahyudi. 2002. Manajemen Sumber Daya Manusia. Jakarta. Sulita.

Bhuono Agung, Nugroho 2005. Strategi Jitu Memilih Metode Statistik Penelitian Dengan SPSS. Yogyakarta. Andi.

Dantes, Dr. Nyoman. 2012. Metedologi Penelitian. Yogyakarta. Andi.

Edy Sutrisno, 2011. Manajemen Sumber Daya Manusia, Jakarta .Kencana.

Hasibuan, Melayu, S.P 2014. Manajemen Sumber Daya Manusia(Edisi Revisi). Bumi Aksara

Husain Umar. 2013. Metode Penelitian Untuk Skripsi dan Tesis Bisnis Edisi Kedua. Jakarta. PT. Bumi Aksara

Istijanto. 2008. Riset Sumber Daya manusia. Jakarta. PT. Gramedia Pustaka Utama

J. Ravianto. 1985. Produktivitas dan tenaga Kerja Indonesia. Jakarta. Lembaga Sarana Informasi Usaha dan Produktivitas.

Jessica Chisnasari, Yuniadi Mayowan. Pengaruh Insentif dan jaminan sosial terhadap produktivitas kerja (studi pada karyawan AJB Bumi Putra 1912 kantor wilayah malang). Malang.

Jhonatan Sarwono. 2005. Teoroi dan Latihan Menggunakan SPSS. Yogyakarta. Andi Yogyakarta

Khoridatul Rifliana. 2014. Pengaruh Jaminan sosial tenaga kerja terhadap produktivitas kerja karyawan pada PT. Teknik Umum Surabaya. Surabaya

Lebrin. 1992 Dalam Hadi. 2007. Pengertian Wawancara

Leni Ayu Novita Sari. 2015. Pengaruh motivasi terhadap produktivitas kerja karyawan. Surakarta 
Manuallang. 2001. Manajemen Sumber Daya Manusia. Yogyakarta. BPFE

Notoatmodjo, S. 2010. Metodologi Penelitian kesehatan. Jakarta. Rineka Cipta

Pangabean, Mutiara. 2007. Manajemen Sumber Daya Manusia. Bogor. Ghalia Indonesia

Prof. Dr. H. Veithzal Rivai, M.B.A \& Ella Jauvani Sagala, S. Psi., M.Sc., 2009. Manajemen Sumber Daya Manusia unruk Perusahaan. Edisi Kedua

Rawi, R. D. P., \& Kadir, M. A. A. (2018). ANALISIS HUBUNGAN MOTIVASI TERHADAP KINERJA PEGAWAI (Studi Kasus Pada Kantor Wali Kota Sorong Papua Barat). MANAJEMEN DEWANTARA, 2(2), 87-94.

Riduan. 2010. Skala Pengukuran Variabel-variabel Penelitian. Bandung. Alfabeta

Rivai, Veithzal. 2009.Manajemen Sumber Daya Manusia Untuk Perusahaan Dari Teori ke Praktik. Jakarta. Raja Grafindo Persada

Setiadi. 2009. Pengaruh Upah dan jaminan sosial terhadap produktivitas kerja karyawan PT. Semarang Makmur. Semarang

Sedarmayanti. 2014. Sumber Daya Manusia dan Produktivitas Kerja. Jakarta. Mandar Maju

Sugiyono, 2008. Metode Penelitian Kuantitatif Kualitatif dan R\&D. Bandung. Alfabeta

Sugiyono. 2010. Metode Penelitian Pendidikan Pendekatan Kuantitatif, kualitatif dan $R \& D$. Bandung. Alfabeta

Yustisia. 2014. Panduan Resmi Memperoleh Jaminan Sosial dari BPJS Ketenagakerjaan. Visi media 